\title{
Impact of impaired fractional flow reserve after coronary interventions on outcomes: a systematic review and meta-analysis
}

Mathias Wolfrum ${ }^{1 \dagger}$, Gregor Fahrni ${ }^{1 \dagger}$, Giovanni Luigi de Maria', Guido Knapp ${ }^{2}$, Nick Curzen ${ }^{3}$, Rajesh K. Kharbanda', Georg M. Fröhlich ${ }^{4}$ and Adrian P. Banning ${ }^{1^{*}}$

\begin{abstract}
Background: FFR is routinely used to guide percutaneous coronary interventions (PCI). Visual assessment of the angiographic result after PCI has limited efficacy. Even when the angiographic result seems satisfactory FFR after a $\mathrm{PCl}$ might be useful for identifying patients with a suboptimal interventional result and higher risk for poor clinical outcome who might benefit from additional procedures. The aim of this meta-analysis was to investigate available data of studies that examined clinical outcomes of patients with impaired vs. satisfactory fractional flow reserve (FFR) after percutaneous coronary interventions (PCI).
\end{abstract}

Methods: This meta-analysis was carried out according to the Cochrane Handbook for Systematic Reviews. The Mantel-Haenszel method using the fixed-effect meta-analysis model was used for combining the results. Studies were identified by searching the literature through mid-January, 2016, using the following search terms: fractional flow reserve, coronary circulation, after, percutaneous coronary intervention, balloon angioplasty, stent implantation, and stenting. Primary endpoint was the rate of major adverse cardiac events (MACE). Secondary endpoints included rates of death, myocardial infarction (MI), repeated revascularisation.

Results: Eight relevant studies were found including a total of 1337 patients. Of those, $492(36.8 \%)$ had an impaired FFR after PCl, and 853 (63.2 \%) had a satisfactory FFR after PCI. Odds ratios indicated that a low FFR following PCI was associated with an impaired outcome: major adverse cardiac events (MACE, OR: 4.95, $95 \%$ confidence interval [Cl]: 3.39-7.22, $p<0.001$ ); death (OR: 3.23, $95 \% \mathrm{Cl}: 1.19-8.76, p=0.022$ ); myocardial infarction (OR: 13.83, $95 \%$ Cl: 4.75-40.24, $p<0.0001$ ) and repeated revascularisation (OR: 4.42, 95 \% Cl: 2.73-7.15, $p<0.0001$ ).

Conclusions: Compared to a satisfactory FFR, a persistently low FFR following PCI is associated with a worse clinical outcome. Prospective studies are needed to identify underlying causes, determine an optimal threshold for post-PCI FFR, and clarify whether simple additional procedures can influence the post-PCI FFR and clinical outcome.

Keywords: Coronary artery disease, Percutaneous coronary interventions, Fractional flow reserve, Intracoronary imaging, Outcome, Meta-analysis

Abbreviations: ACS, Acute coronary syndrome; AUC, Area under curve; BMS, Bare metal stent; CAD, Coronary artery disease; Cl, Confidence interval; DES, Drug eluting stent; FFR, Fractional flow reserve; iFR, Instantaneous wave-free ratio; IVUS, Intravascular ultrasound; MACE, Major adverse cardiac events; MSA, Minimal stent area; OCT, Optical coherence tomography; PCl, Percutaneous coronary intervention; POBA, Plain old balloon angioplasty; ROC, Receiver operating characteristic curve; TLR, Target lesion revascularisation; TVF, Target vessel failure; TVR, Target vessel revascularisation

\footnotetext{
* Correspondence: adrian.banning@ouh.nhs.uk

${ }^{\dagger}$ Equal contributors

${ }^{1}$ Oxford Heart Centre, Oxford University Hospitals, Headley Way, Oxford

OX39DU, UK

Full list of author information is available at the end of the article
}

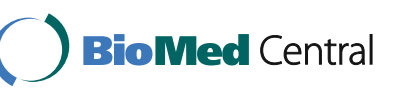

(c) 2016 The Author(s). Open Access This article is distributed under the terms of the Creative Commons Attribution 4.0 International License (http://creativecommons.org/licenses/by/4.0/), which permits unrestricted use, distribution, and reproduction in any medium, provided you give appropriate credit to the original author(s) and the source, provide a link to the Creative Commons license, and indicate if changes were made. The Creative Commons Public Domain Dedication waiver (http://creativecommons.org/publicdomain/zero/1.0/) applies to the data made available in this article, unless otherwise stated. 


\section{Background}

Fractional flow reserve (FFR) is the established gold standard used in the cardiac catheterisation laboratory to assess the ischemic burden associated with an atheromatous lesion of the coronary arteries. Evidence from various clinical scenarios has shown that an FFR-guided PCI strategy reduces the need for stenting and improves clinical outcomes. Therefore, FFR has been incorporated in current revascularisation guidelines [1-3]. With improved wire technology, it is increasingly cost effective and timesaving to use the pressure wire for diagnosis and as the platform for any subsequent PCI [4]. Nevertheless, postPCI FFR measurement has not yet become part of established clinical practice and only a minority of operators (22\%) consider FFR to evaluate the post-stenting result [5].

Visual assessment, by angiography and quantitative coronary angiography (QCA), has limited efficacy with respect to identifying patients with suboptimal PCI results and subsequent worse clinical outcomes [6, 7]. Even with an angiographic satisfactory result after PCI 19-32\% of these patients experience an adverse cardiovascular event during a 2-year follow-up [8]. Post-PCI FFR measurement might be a useful indicator for the identification of a suboptimal PCI result and, if so, would be beneficial to both operator and patient. Of note, a recent small prospective interventional study provides evidence that the post-PCI FFR helps to identify patients that might benefit from further optimisation procedures in order to improve clinical outcome [9].

However, the value of post-PCI FFR might be confounded by several factors, such as gender [10] and comorbidities [11]. The subsequent cut-off for a satisfactory post-PCI FFR might differ among patient populations. As the clinical impact of post-PCI FFR has not been determined in larger scale trials this meta-analysis was setup to examine existing data pertaining to post-PCI FFR measurement and its association with clinical outcome.

\section{Methods}

This study was carried according to current recommendations of the Cochrane Handbook for Systematic Reviews and the Meta-analysis of Observational Studies in Epidemiology recommendations (MOOSE checklist, Additional file 1: Table S1) [12]. Two authors (MW, GF) planned and designed this meta-analysis evaluating the association between FFR post PCI and clinical outcomes and created an electronic database with variables of interest.

\section{Search strategy}

Medline, BIOS, and ISI Web of Science databases were searched through January 14, 2016. Additionally, editorials and web-based information sources (http:// www.tctmd.com, http://www.theheart.org, http://www. europcronline.com, http://www.cardiosource.com, and http://www.crtonline.com) were screened. The following search terms were used: fractional flow reserve, coronary circulation, after, percutaneous coronary intervention, balloon angioplasty, stent implantation, and stenting. Reference lists of the selected articles were checked for other relevant citations. A more detailed search strategy for Medline can be found in the Additional file 1: Table S2.

\section{Study selection}

Studies included in the meta-analysis were published in full text and in English. Only studies where it was possible to clearly categorise patients into groups with low and high post-PCI FFR were included. Two authors (MW, GF) independently identified appropriate articles. Disagreements were discussed, and a third author (GMF) was consulted in unclear cases. All included studies were approved by the local ethics committees and were in compliance with the Helsinki Declaration.

\section{Data extraction and quality assessment}

Relevant information from each study, retrieved using a dedicated standardised database, included study design, baseline clinical characteristics of the study population, and clinical outcomes. Study quality was ascertained according to the Cochrane Handbook [12], but without using a quality score, due to the limitations associated with this approach [13].

\section{Endpoints and definitions}

Primary endpoint was the rate of major adverse cardiac events (MACE) at longest follow-up. MACE was defined according to the individual study (Table 1). Secondary endpoints included rates of death, myocardial infarction (MI), repeated revascularisation (repeated PCI, target vessel revascularisation [TVR], target lesion revascularisation [TLR] and CABG) and in-stent restenosis.

\section{Data synthesis and analysis}

Odds ratio and $95 \%$ confidence intervals (CIs) for binary outcomes were calculated. Since we mostly deal with rare events, Mantel-Haenszel method was used for combining the results [14]. The method can include single-zero and double-zeroes studies. The fixed-effect meta-analysis model was used as no relevant between-study variance was observed (see Additional file 1: Table S3). Weighted incidence of events is presented for both groups calculated according to random-effects meta-analysis for proportions with the Knapp-Hartung adjustment $[14,15]$. Given the limitations for the assessment of publication bias in meta-analysis with a small study number using Funnel plots the Egger's test and Begg's rank correlation test were applied (Additional file 1: Table S4) $[16,17]$.

Sensitivity analyses excluded the study by Bech et al. [18], which used only plain old balloon angioplasty (POBA) 
Table 1 Characteristics of included studies

\begin{tabular}{|c|c|c|c|c|c|c|c|}
\hline \multirow{2}{*}{$\begin{array}{l}\text { First author, year } \\
\text { of publication }\end{array}$} & \multirow[t]{2}{*}{ Design } & \multirow[t]{2}{*}{ Indication for $\mathrm{PCl}$} & \multirow[t]{2}{*}{$\mathrm{PCl}$ technique } & \multirow{2}{*}{$\begin{array}{l}\text { Cut-off } \\
\text { for low } \\
\text { FFR - group }\end{array}$} & \multicolumn{2}{|c|}{ FFR technique } & \multirow[t]{2}{*}{ Definition of MACE } \\
\hline & & & & & Adenosine & $\begin{array}{l}\text { Pressure wire } \\
\text { pullback }\end{array}$ & \\
\hline Bech et al., [18] & Retrospective & Stable angina & POBA & $<0.9$ & i.v. & NA & $\begin{array}{l}\text { MACE (death, MI, recurrent } \\
\text { angina, CABG, repeated PTCA }\end{array}$ \\
\hline Pijls et al., [31] & $\begin{array}{l}\text { Prospective, } \\
\text { observational }\end{array}$ & All comers & "stent" (type NA) & $\leq 0.9$ & i.v. or i.c. & No & MACE (death, MI, CABG, TVR) \\
\hline Klauss et al., [30] & Retrospective & Stable angina & BMS & $<0.95$ & i.c. & Not mandatory & MACE (death, MI, TVR) \\
\hline Nam et al., [19] & Retrospective & $\begin{array}{l}2 / 3 \text { ACS, } 1 / 3 \\
\text { stable angina }\end{array}$ & DES & $\leq 0.9$ & i.c. & No & MACE (death, MI, TVR) \\
\hline Leesar et al., [9] & $\begin{array}{l}\text { Prospective, } \\
\text { interventional }\end{array}$ & Stable angina & $\mathrm{DES}>\mathrm{BMS}$ & $<0.96$ & i.c. & No & MACE (death, MI, TLR) \\
\hline Ito et al., [23] & Retrospective & $\begin{array}{l}92 \% \text { stable angina, } \\
8 \% \text { unstable angina }\end{array}$ & DES plus IVUS & $\leq 0.9$ & i.c. & No & $\begin{array}{l}\text { MACE (cardiac death, MI, TVR, } \\
\text { stent thrombosis) }\end{array}$ \\
\hline Reith et al., [24] & $\begin{array}{l}\text { Prospective, } \\
\text { observational }\end{array}$ & Stable angina & $\begin{array}{l}\text { DES }>\text { BMS } \\
\text { plus OCT }\end{array}$ & $\leq 0.905$ & i.c. & No & MACE (death, MI, TLR) \\
\hline Doh et al., [22] & $\begin{array}{l}\text { Prospective, } \\
\text { observational }\end{array}$ & $\begin{array}{l}1 / 3 \text { ACS, } 2 / 3 \\
\text { stable angina }\end{array}$ & DES plus IVUS & $<0.89$ & i.v. or i.c. & Not mandatory & $\begin{array}{l}\text { TVF (death and MI attributed } \\
\text { to target vessel, TVR) }\end{array}$ \\
\hline
\end{tabular}

Abbreviations: $A C S$ acute coronary syndrome, $A U C$ area under curve, $B M S$ bare metal stent, $C A B G$ coronary artery bypass graft, $C I$ confidence interval, $D E S$ drug eluting stent, i.c. intracoronary, i.v. intravenous, IVUS intravascular ultrasound, FFR fractional flow reserve, FU follow up, MACE major adverse cardiac events, $M I$ myocardial infarction, Mo months, $N$ patient number, NA not applicable, OCT optical coherence tomography, TLR target lesion revascularisation, TVF target vessel failure, TVR target vessel revascularisation, $P C I$ percutaneous coronary intervention, $P O B A$ plain old balloon angioplasty

for the endpoints. Because a post-PCI FFR $<0.9$ has been identified as an optimal predictor of a worse clinical outcome [19], one analysis considered only studies with an FFR cut-off of 0.9 between low and high FFR groups. All meta-analyses were carried out using the package metafor in the statistical software package R, version 3.2.3 [20, 21].

\section{Results}

\section{Included studies}

A total of eight studies with 1337 patients met our inclusion criteria: four prospective studies (983 patients) and four retrospective studies (354 patients), published between
1999 and 2015 (Fig. 1). Study and population characteristics are presented in Tables 1 and 2.

\section{Main outcomes \\ MACE}

MACE rate was defined (Table 1) and reported by all included studies. The overall weighted incidence for MACE was 21.4 (95 \% CI: 17.0-25.8 \%) in the low FFR group and 5.0 (95\% CI: 3.5-6.4\%) in the high FFR group (Fig. 2a). A low FFR after PCI was associated with significantly higher odds for MACE (OR: 4.95, 95 \% CI: 3.39-7.22, $p<0.001)$.

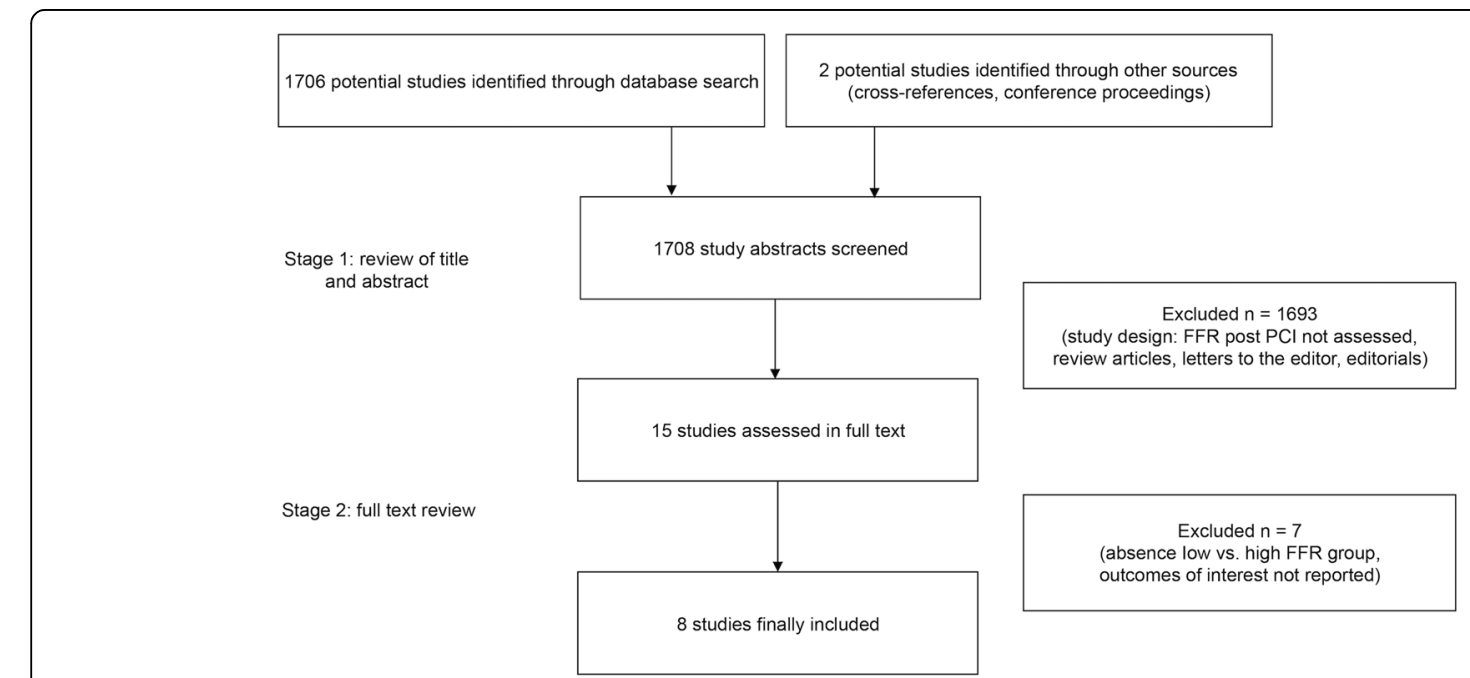

Fig. 1 Study selection process. FFR - fractional flow reserve, PCl - percutaneous coronary intervention 
Table 2 Patient characteristics

\begin{tabular}{|c|c|c|c|c|c|c|c|c|c|c|c|c|c|c|c|c|c|c|}
\hline \multirow[b]{2}{*}{ FFR group } & \multicolumn{2}{|c|}{ Bech et al. } & \multicolumn{2}{|c|}{ Pijls et al. } & \multicolumn{2}{|c|}{ Klauss et al. } & \multicolumn{2}{|c|}{ Nam et al. } & \multicolumn{2}{|c|}{ Leesar et al. } & \multicolumn{2}{|c|}{ Ito et al. } & \multicolumn{2}{|c|}{ Reith et al. } & \multicolumn{2}{|c|}{ Doh et al. } & \multicolumn{2}{|c|}{ Combined } \\
\hline & Low & High & Low & High & Low & High & Low & High & Low & High & Low & High & Low & High & Low & High & Low & High \\
\hline$N$ & 32 & 26 & 237 & 507 & 53 & 66 & 40 & 40 & 31 & 35 & 53 & 44 & 26 & 40 & 20 & 95 & 492 & 853 \\
\hline \multirow[t]{2}{*}{ Age (years) (SD) } & \multirow[t]{2}{*}{61.5} & & \multirow{2}{*}{\multicolumn{2}{|c|}{$62(11)$}} & \multirow{2}{*}{\multicolumn{2}{|c|}{$62(10)$}} & \multirow[t]{2}{*}{$62(10)$} & \multirow[t]{2}{*}{$63(8)$} & \multirow[t]{2}{*}{$63(11)$} & \multirow[t]{2}{*}{$60(12)$} & \multirow{2}{*}{\multicolumn{2}{|c|}{$71(9)$}} & \multirow[t]{2}{*}{$69(10)$} & \multirow[t]{2}{*}{$69(10)$} & \multirow{2}{*}{\multicolumn{2}{|c|}{$64(9)$}} & $65(4)$ & $64(4)$ \\
\hline & & & & & & & & & & & & & & & & & $64(4)$ & \\
\hline \multirow[t]{2}{*}{ Male (\%) } & \multirow[t]{2}{*}{69} & & \multirow{2}{*}{\multicolumn{2}{|c|}{ NA }} & \multirow{2}{*}{\multicolumn{2}{|c|}{75}} & \multirow[t]{2}{*}{78} & \multirow[t]{2}{*}{70} & 77 & 70 & 75 & & 88 & 75 & 83 & & 80 & 77 \\
\hline & & & & & & & & & & & & & & & & & 77 & \\
\hline HTN (\%) & 33 & & 51 & & 79 & & 58 & 43 & 68 & 94 & 92 & & 65 & 88 & 82 & & 63 & 74 \\
\hline & & & & & & & & & & & & & & & & & 61 & \\
\hline Diabetes (\%) & 17 & & 24 & & 26 & & 20 & 8 & 32 & 23 & 37 & & 58 & 53 & 51 & & 34 & 28 \\
\hline & & & & & & & & & & & & & & & & & 28 & \\
\hline HC (\%) & 31 & & 61 & & 83 & & 10 & 15 & 58 & 74 & 85 & & 54 & 60 & 68 & & 37 & 49 \\
\hline & & & & & & & & & & & & & & & & & 61 & \\
\hline Smoking (\%) & 24 & & 48 & & 38 & & 28 & 48 & 32 & 46 & 54 & & 15 & 23 & 30 & & 26 & 38 \\
\hline & & & & & & & & & & & & & & & & & 41 & \\
\hline $\mathrm{FHx}(\%)$ & 41 & & 38 & & 38 & & NA & & NA & & NA & & 39 & 63 & NA & & 40 & \\
\hline Prior MI (\%) & 17 & & NA & & 56 & & 10 & 13 & NA & & NA & & NA & & 5.6 & & 25 & \\
\hline MVD (\%) & NA & & NA & & 67 & & 63 & 60 & NA & & NA & & 73 & 68 & 63 & & 67 & 64 \\
\hline & & & & & & & & & & & & & & & & & 65 & \\
\hline LAD (\%) & 66 & & 52 & & 39 & & 83 & 55 & 39 & 34 & 56 & & NA & & 100 & 71 & 71 & 59 \\
\hline & & & & & & & & & & & & & & & & & 54 & \\
\hline Complex lesionª (\%) & NA & & NA & & 65 & & 90 & 78 & NA & & NA & & NA & & 95 & 67 & 92 & 70 \\
\hline & & & & & & & & & & & & & & & & & 72 & \\
\hline FU (months) & 24 & & 6 & & 6 & & 12 & & 24 & & 18 & & 20 & & 23 & & 16 & \\
\hline
\end{tabular}

Separate data provided for low FFR group and high FFR group if available from respective study, otherwise overall value Abbreviations: FHx family history, FFR fractional flow reserve, FU follow up, HC hypercholesterolemia, HTN Hypertension, LAD left anterior descending artery, $M I$ myocardial infarction, $M V D$ multi-vessel-disease, $N$ patient number, $S D$ standard deviation

${ }^{a}$ Complex lesion is defined as B2 or C category according to American College of Cardiology/American Heart Association (ACC/AHA) lesion classification

\section{Death}

Overall rate of death was reported by seven studies involving 1230 patients. The weighted incidence for overall death was $1.7 \%$ (95\% CI: 0.6-2.9\%) in the low FFR group and $0.8 \%$ (95\% CI: $0.0-1.7 \%$ ) in the high FFR group (Fig. 2b). A low FFR after PCI was associated with significantly higher risk of death (OR: 3.23, 95 \% CI: $1.19-8.76, p=0.022$ ).

\section{Myocardial infarction}

The event rate for MI was reported by all included studies. The weighted incidence for MI was 3.3 (95\% CI: $1.1-$ $5.6 \%$ ) in the low FFR group and $0.8 \%$ (95 \% CI: 0.2-1.4 \%) in the high FFR group (Fig. 2c). A low FFR after PCI was associated with significantly higher risk of MI during follow-up (OR: 13.83, 95 \% CI: 4.75-40.24, $p<0.0001$ ).

\section{Repeated revascularisation}

Data for repeated revascularisation was available for repeated PCI from three studies, and for CABG from 5 studies. There was an increased risk for repeated revascularisation for patients in the low FFR group, compared to patients in the high FFR group (OR: 4.42, 95 \% CI: 2.73-7.15, $p<0.0001$, Fig. 2d): repeated PCI (OR: 3.81, 95 \% CI: 2.26-6.43, $p<0.0001$ ), CABG (OR: 6.35, 95 \% CI: 1.96-20.54, $p=0.002$,). Four studies included data about TVR [9, 19, 22, 23], and two studies about TLR [9, 24], and these indicated that the risk for both endpoints was higher for patients with impaired FFR after PCI: TVR (OR: 3.40, $95 \%$ CI: 1.44-8.03, $p=0.005$ ), TLR (OR: 5.48, $95 \% \mathrm{CI}$ : $1.12-26.78, p=0.036)$. Two studies reported the rate of in-stent restenosis $[9,19]$. The weighted incidence for in-stent restenosis was $16.9 \%$ (95\% CI: 8.2-25.6\%) in the low FFR group and 3.4\% (95\% CI: $0.0-7.5 \%)$ in the high FFR group. A low FFR after PCI was associated with significantly higher risk of in-stent restenosis (OR: 4.93, 95 \% CI: 1.32-18.37, $p=0.018$ ).

\section{Sensitivity analysis}

After excluding the study by Bech et al. [18], the results still demonstrated that patients with a low post-PCI FFR 


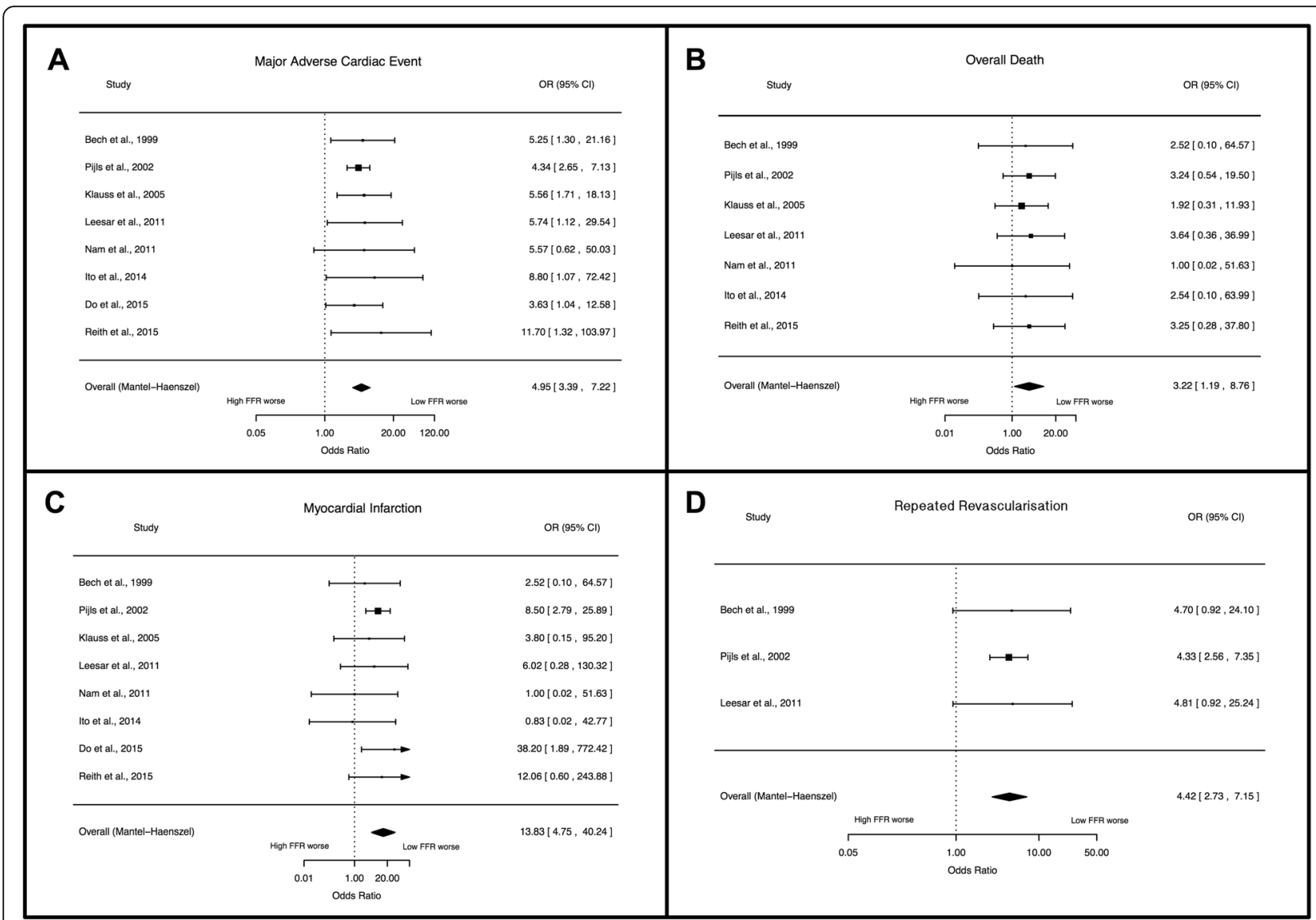

Fig. 2 Forest plots of odds ratios (OR) for major adverse cardiac events (MACE, Panel a), death (Panel b), myocardial infarction (Panel c) and repeated revascularisation (Panel d). Markers represent point estimates of odds ratios, marker size represents study weight. Horizontal bars indicate $95 \%$ confidence intervals (CI). FFR - fractional flow reserve

had a significantly higher risk for all main outcomes than patients in the high FFR group (Additional file 1: Figure S1): MACE (OR: 4.93, $95 \%$ CI: 3.33-7.29, $p<$ 0.0001 ), death (OR: $3.03,95 \% \mathrm{CI}: 1.11-8.28, p=0.03)$, MI (OR: $13.45,95 \%$ CI: 4.63-39.05, $p<0.0001$ ) and repeated PCI (OR: 3.96, 95 \% CI: 2.29-6.85, $p<0.0001$ ). When only studies with an FFR cut-off of 0.9 were included (Additional file 1: Figure S2), the results showed that patients in the low FFR group had significantly higher risk than the high FFR group for MACE (OR: 4.92, $95 \%$ CI: 3.11-7.78, $p<0.0001)$, myocardial infarction (OR: 10.02 , $95 \%$ CI: 3.33-30.12, $p<0.0001$ ), and a statistical trend towards higher risk for overall death (OR: 3.70, $95 \%$ CI: 0.89-15.43, $p=0.073$ ). Other endpoints were not included in this analysis, as the number of appropriate studies was $\leq 2$.

\section{Discussion}

Post-PCI FFR as an indicator of clinical outcome

Results of the meta-analysis reported herein, which included different clinical scenarios and data from different era of interventional cardiology, support the hypothesis that a persistently low FFR following PCI is associated with an adverse clinical outcome. We found that patients with an impaired post-PCI FFR had significantly increased risk for the primary endpoint of MACE, as well as for the secondary endpoints of death, myocardial infarction, and repeat revascularization (PCI and CABG). These results were not changed by the exclusion of data from one study that used only POBA [18], a technique known to convey a higher risk for MACE than stenting [25, 26].

Data supporting present findings of the primary endpoint of MACE comes from a study by Johnson et al. [27], which primarily studied the continuous relationship between pre-PCI FFR and clinical outcomes. A small sub-analysis of this study focused on FFR measured immediately after stenting and showed that low FFR is inversely correlated with subsequent adverse events in both continuous (Cox hazard ratio: $0.86,95 \%$ CI: $0.80-0.93 ; P<0.001)$ and tertile $(\log -\operatorname{rank} P<0.001)$ analyses.

\section{Causes of persistently low FFR after PCI}

A number of factors can cause a post-PCI pressure drop over a treated epicardial segment, eventually leading to an 
impaired FFR, including incomplete stent expansion, stent malapposition, "geographical miss," plaque protrusion, edge dissection, and plaque shift at the stent edge (Fig. 3).

The pathophysiological concept is explained by the Hagen-Poiseuille law (e.g. if malapposition or plaque protrusion is present): the pressure loss is caused by viscous friction along a treated segment. Additionally, e.g. if incomplete stent-expansion or geographical miss is considered the Bernoulli's law can be applied. In this scenario residual narrowing leads to a conversion of pressure into kinetic energy. As a substantial amount of energy is lost due to the presence of turbulent flow not the entire coronary pressure can be recovered at the exit of the target lesion. Even without a significant narrowing a suboptimal PCI result can cause turbulent flow within and beyond the treated coronary segment (stent malapposition, plaque protrusion, edge dissection, plaque shift at the stent edge), especially during the hyperaemic phase of FFR assessment, when high flow rates of blood are induced. The switch from laminar to turbulent flow results in the formation of eddies and a dramatic increase in flow resistance, leading to a pressure drop downstream from the treated coronary segment. The total pressure loss during hyperaemia causes the impaired FFR.

The first study to establish a link between a persistent pressure gradient and a suboptimal stent result was published by Hanekamp et al., who used quantitative coronary angiography, intravascular ultrasound, and coronary pressure measurement to assess deployment of coil stents
[28]. They found a close relationship between poor PCI results, such as stent underexpansion and/or malapposition, and suboptimal stent symmetry, and in-stent gradients. Another study using slotted-tube stents found that a post-stent FFR $<0.96$ predicted a suboptimal stent result identified by IVUS [29]. In $70 \%$ of those patients, a low post-stent FFR was linked to incomplete stent expansion. Studies using drug eluting stents confirmed a substantial rate of under-expanded stents in patients with low poststent FFR, despite reasonable angiographic results [22, 30]. One of these studies found that low post-stent FFR correlated with adverse clinical outcomes at three years [22].

A number of additional factors can affect the final results of stent implantation and account for the relationship between post-PCI FFR and clinical outcome. Ito et al. suggested a link between high residual plaque volume, identified by IVUS, and impaired post-stent FFR after DES implantation [23]. Patients with high residual plaque had a significantly higher rate of MACE after 18 months.

Lesion complexity may also affect the final result of stentimplantation. Two included studies of our meta-analysis reported a significant lower FFR in patients with complex lesions [19, 22]. In both studies a low FFR post PCI was associated with a significantly higher rates of MACE rates (Table 2). Stent dimensions were also reported to influence post-stent FFR and clinical outcome $[19,22,31]$. Stents with greater length or smaller diameter were significantly correlated with a low post-stent FFR and higher MACE rates. These observations might

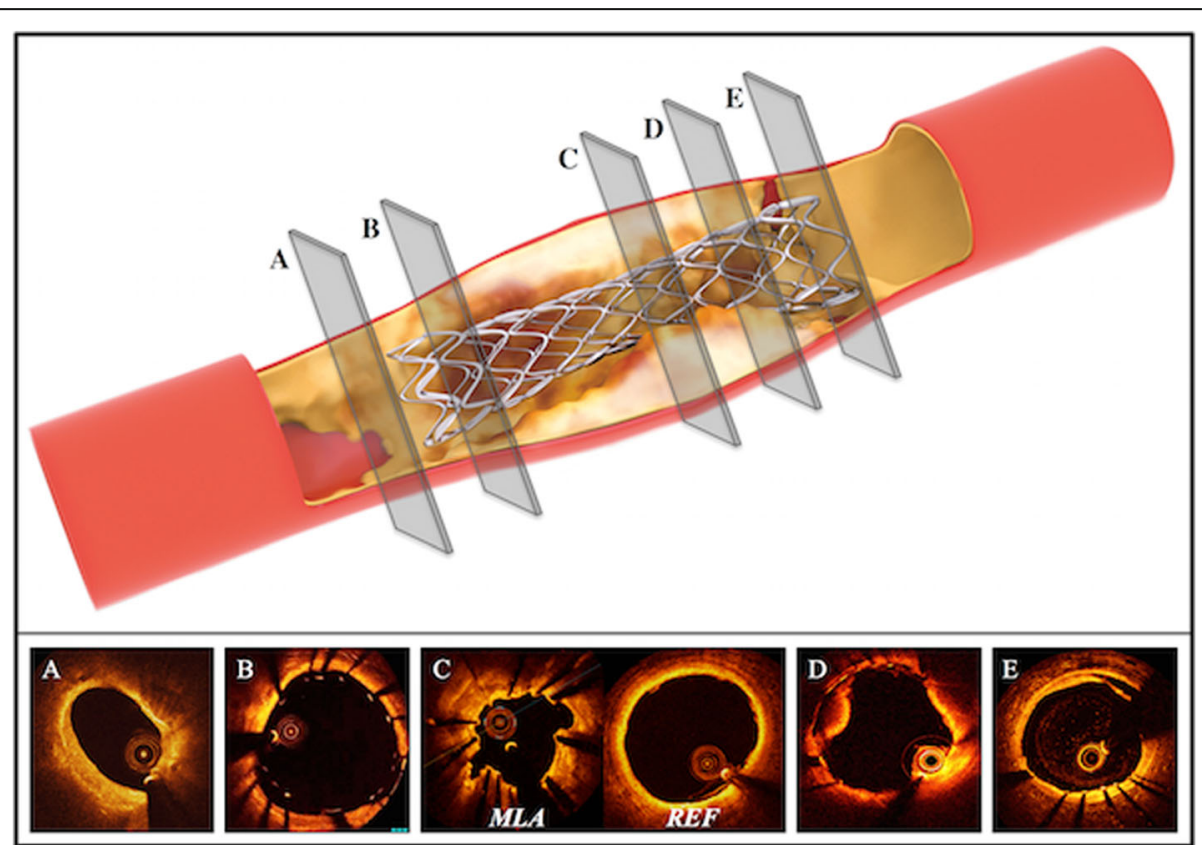

Fig. 3 Potential causes of suboptimal FFR after percutaneous coronary interventions. Panel a 'geographical miss' (diseased reference segment). Panel b stent mal-apposition. Panel $\mathbf{c}$ stent under-expansion. Panel $\mathbf{d}$ intrastent plaque-protrusion/thrombus. Panel e edge dissection. MLA - minimal lumen area, REF - proximal reference segment 
help to explain the previously described association between these characteristics in BMS and DES procedures and higher subsequent event rates [32-34].

Variations in post-PCI FFR and ultimately outcome seem to be linked to different coronary arteries. A suboptimal post-stent FFR was more frequent in patients with a PCI to the left anterior descending (LAD) artery than to the right coronary artery or left circumflex $[19,22]$. This finding presumably reflects the larger myocardial territory subtended by the LAD, leading to greater peak flow and lower post-stent FFR for any given residual stenosis in this vessel. Interestingly, in the aforementioned studies an impaired post-PCI FFR was associated with higher rate of MACE.

\section{Potential clinical application of the results}

Based on the results of our meta-analysis, use of a pressure wire to check the PCI result seems to be a promising concept, even after PCI with an apparently satisfactory angiographic result. Measurement of post-PCI FFR is especially appropriate when a pressure wire was used before PCI to guide the treatment strategy. If FFR remains low after PCI and a pressure wire pullback manoeuvre during maximal hyperaemia demonstrates a step increase of pressure within or close to the stent edges subsequent intravascular imaging might provide the ability to identify causes of suboptimal post-PCI FFR (Fig. 3). Based on the result of imaging, simple additional procedures could improve the interventional result. However, only one small previous study has prospectively examined whether additional interventions can reduce the risk of future MACE in patients with low post-PCI FFR [9]. Their results suggested that consistent postdilatation after coronary stenting in patients with a post-stent FFR $\geq 0.96$ could achieve consequently favourable clinical outcomes in $53 \%$ of patients.

In contrast, a continuous gradual reduction in FFR during pressure wire pullback manoeuvre along the course of the coronary artery suggests diffuse CAD. The observation of diffuse CAD may not be evident from an angiographic examination, but can lead to severely impaired FFR $(<0.75)$, with myocardial ischemia and high rates of MACE [35]. For example, diffuse CAD is more common in patients with diabetes mellitus and, in these patients, is often associated with impaired post-stent FFR, despite an angiographically optimal PCI [36]. Thus, low post-stent FFR without a notable point of decrease could indicate advanced diffuse CAD, associated with a relatively high MACE rate. This is an important finding as further interventional optimisation of PCI is not a promising option for diffuse CAD and should be deferred. Patients with diffuse CAD might benefit from a stronger medical secondary prevention or from prolonged dual antiplatelet therapy. However, at current stage these strategies are only hypothetical and need validation in large scale randomised clinical trials.

\section{Study limitations}

Most of the studies included in the meta-analysis were retrospective or observational and, therefore, were subject to patient selection bias, lack of independent event adjudication, heterogeneity in event definitions, and differences in the duration of follow-up (Tables 1 and 2). With the exception of one large multicenter registry [31], most of the studies had small sample sizes, ranging from 60 to 119 patients. Most studies had no restrictions with regard to co-morbidities, which led to a generally heterogeneous patient population (Table 2).

The existing data on post-PCI FFR covers a wide range of coronary interventions, including POBA, BMS, and first and second generation DES (Table 1). Because different stent designs differentially affect blood flow and post-stent FFR, the results must be considered hypothesis-generating. Furthermore, induction of hyperaemic FFR was accomplished by intracoronary adenosine in the majority of trials, so the results cannot entirely be compared to cases using intravenous adenosine, especially in combination with pressure wire pullback.

Some of the studies included in the meta-analysis used different cut-off points to distinguish between low and high FFR groups. Therefore, we included a sensitivity analysis that considered only studies with an FFR cut-off of 0.9, the value identified as an optimal predictor for a worse clinical outcome following PCI [19]. The results demonstrated a significantly higher risk for patients in the low FFR group for MACE and myocardial infarction, and a trend towards a higher risk for overall death. However, prospective validation of this cut-off is an important future challenge. It is conceivable that the optimal cut-off will vary among different coronary arteries and different clinical scenarios, similar to results of FFR assessment before PCI [27].

Furthermore, current data provides evidence only for the use of conventional FFR. However, alternative modes of physiological assessment are promising such as the instantaneous wave-free ratio (iFR). iFR assess the severity of a coronary stenosis using a pressure wire without the need for potent vasodilators. This might be an advantage over FFR as it obviates the need for adenosine, which is contraindicated in some patients and could safe time and costs in the cathlab. Especially with the introduction of iFR pullback (iFR Scout ${ }^{\mathrm{tw}}$, Volcano Corporation, San Diego, California) it seems to be a promising concept for the assessment of the PCI result. However, no data exists on this topic yet and further research is strongly warranted.

\section{Conclusion}

Results of the meta-analysis presented herein provide evidence that a persistently low FFR following PCI is 
associated with an adverse clinical outcome. Prospective studies are warranted to determine an optimal threshold (or thresholds, in different scenarios) for post-PCI FFR. Observational studies using intra-coronary imaging, such as IVUS and OCT, have suggested different underlying causes for a suboptimal FFR. Large prospective studies are needed to confirm that these are the responsible mechanisms and to examine whether additional simple procedures can influence post-stent FFR and potentially improve clinical outcome.

\section{Additional file}

Additional file 1: This supplement contains additional methods and

results. (DOC $856 \mathrm{~kb}$ )

\section{Acknowledgements}

Not applicable.

\section{Funding}

GF was supported by fellowship grants from the Bangerter- Rhyner-Stiftung, Freiwillige Akademische Gesellschaft Basel, and NIHR Oxford Biomedical Research Centre.

\section{Availability of data and materials}

The datasets supporting the conclusions of this article are included within the article and in the Additional file 1.

\section{Authors' contributions}

$A B, N C$ and MW had the original idea for the study. The protocol was designed and refined by $A B, N C, R K, M W, G M F$ and GM. The literature search and data collection was performed by MW, GF and GMF. GK led the statistical analysis. All authors contributed to the interpretation of the data. MW and GF wrote the initial draft of the manuscript. All authors contributed to this paper significantly and approved the final version of the manuscript.

\section{Competing interests}

Professor Banning has received an unrestricted research funding from Boston Scientific. No other authors have relationships relevant to the contents of this paper.

\section{Consent for publication}

Not applicable.

\section{Ethics approval and consent to participate}

This systematic review and meta-analysis included only studies that had ethical approval and followed the provisions stated in the Declaration of Helsinki.

\section{Author details}

'Oxford Heart Centre, Oxford University Hospitals, Headley Way, Oxford OX39DU, UK. ²Department of Statistics, TU University Dortmund, Dortmund, Germany. ${ }^{3}$ University Hospital Southampton NHS Foundation Trust, Southampton, UK. ${ }^{4}$ Department of Cardiology, Charité Universitätsmedizin Berlin (Campus Benjamin Franklin), Berlin, Germany.

Received: 26 May 2016 Accepted: 26 August 2016

\section{Published online: 08 September 2016}

\section{References}

1. Fihn SD, Gardin JM, Abrams J, Berra K, Blankenship JC, Dallas AP, Douglas PS, Foody JM, Gerber TC, Hinderliter AL, King III SB, Kligfield PD, Krumholz HM, Kwong RY, Lim MJ, Linderbaum JA, Mack MJ, Munger MA, Prager RL, Sabik JF, Shaw LJ, Sikkema JD, Smith Jr CR, Smith Jr SC, Spertus JA, Williams SV, Anderson JL. CCF/AHA/ACP/AATS/PCNA/SCAI/STS guideline for the diagnosis and management of patients with stable ischemic heart disease: a report of the American College of Cardiology Foundation/American Heart Association task force on practice guidelines, and the American College of Physicians, American Association for Thoracic Surgery, Preventive Cardiovascular Nurses Association, Society for Cardiovascular Angiography and Interventions, and Society of Thoracic Surgeons. Circulation. 2012;126(25):e354-471.

2. Fihn SD, Blankenship JC, Alexander KP, Bittl JA, Byrne JG, Fletcher BJ, Fonarow GC, Lange RA, Levine GN, Maddox TM, Naidu SS, Ohman EM, Smith PK. ACC/AHA/AATS/PCNA/SCAI/STS focused update of the guideline for the diagnosis and management of patients with stable ischemic heart disease: a report of the American College of Cardiology/American Heart Association Task Force on Practice Guidelines, and the American Association for Thoracic Surgery, Preventive Cardiovascular Nurses Association, Society for Cardiovascular Angiography and Interventions, and Society of Thoracic Surgeons. Circulation. 2014;130(19):1749-67

3. Windecker S, Kolh P, Alfonso F, Collet JP, Cremer J, Falk V, Filippatos G, Hamm C, Head SJ, Juni P, Kappetein AP, Kastrati A, Knuuti J, Landmesser U, Laufer G, Neumann FJ, Richter DJ, Schauerte P, Sousa Uva M, Stefanini GG, Taggart DP, Torracca L, Valgimigli M, Wijns W, Witkowski A. 2014 ESC/EACTS Guidelines on myocardial revascularization: The Task Force on Myocardial Revascularization of the European Society of Cardiology (ESC) and the European Association for Cardio-Thoracic Surgery (EACTS)Developed with the special contribution of the European Association of Percutaneous Cardiovascular Interventions (EAPCI). Eur Heart J. 2014;35(37):2541-619.

4. Fearon WF, Bornschein B, Tonino PA, Gothe RM, Bruyne BD, Pijls NH, Siebert U. Economic evaluation of fractional flow reserve-guided percutaneous coronary intervention in patients with multivessel disease. Circulation. 2010;122(24):2545-50.

5. Tebaldi M, Biscaglia S, Pecoraro A, Fineschi M, Campo G. Fractional flow reserve implementation in daily clinical practice: A European survey. Int J Cardiol. 2016;207:206-7.

6. Rensing BJ, Hermans WR, Vos J, Tijssen JG, Rutch W, Danchin N, Heyndrickx GR, Mast EG, Wijns W, Serruys PW. Luminal narrowing after percutaneous transluminal coronary angioplasty. A study of clinical, procedural, and lesional factors related to long-term angiographic outcome. Coronary Artery Restenosis Prevention on Repeated Thromboxane Antagonism (CARPORT) Study Group. Circulation. 1993;88(3):975-85.

7. Strauss BH, Escaned J, Foley DP, di Mario C, Haase J, Keane D, Hermans WR, de Feyter PJ, Serruys PW. Technologic considerations and practical limitations in the use of quantitative angiography during percutaneous coronary recanalization. Prog Cardiovasc Dis. 1994;36(5):343-62.

8. Valgimigli M, Tebaldi M, Borghesi M, Vranckx P, Campo G, Tumscitz C, Cangiano E, Minarelli M, Scalone A, Cavazza C, Marchesini J, Parrinello G. Two-year outcomes after first- or second-generation drug-eluting or baremetal stent implantation in all-comer patients undergoing percutaneous coronary intervention: a pre-specified analysis from the PRODIGY study (PROlonging Dual Antiplatelet Treatment After Grading stent-induced Intimal hyperplasia studY). JACC Cardiovasc Interv. 2014;7(1):20-8.

9. Leesar MA, Satran A, Yalamanchili V, Helmy T, Abdul-Waheed M, Wongpraparut $\mathrm{N}$. The impact of fractional flow reserve measurement on clinical outcomes after transradial coronary stenting. Eurolntervention. 2011;7(8):917-23.

10. Fineschi M, Guerrieri G, Orphal D, Palmerini E, Münzel T, Warnholtz A, Pierli C, Gori T. The impact of gender on fractional flow reserve measurements. Eurolntervention. 2013;9(3):360-6.

11. Tebaldi M, Biscaglia S, Fineschi M, Manari A, Menozzi M, Secco GG, Di Lorenzo E, D'Ascenzo F, Fabbian F, Tumscitz C, et al. Fractional flow reserve evaluation and chronic kidney disease: Analysis from a multicenter Italian registry (the FREAK study). Catheter Cardiovasc Interv. 2015 [Epub ahead of print].

12. Higgins JPT, Green S. Cochrane Handbook for Systematic Reviews of Interventions Version 5.1.0 [updated March 2011]. The Cochrane Collaboration; 2011. http://training.cochrane.org/handbook. Access 12 Jan 2016

13. Juni $P$, Witschi $A$, Bloch $R$, et al. The hazards of scoring the quality of clinical trials for meta-analysis. JAMA. 1999;282(11):1054-60.

14. Bohning D, Mylona K, Kimber A. Meta-analysis of clinical trials with rare events. Biom J. 2015;57(4):633-48

15. Veroniki AA, Jackson D, Viechtbauer W, Bender R, Knapp G, Kuss O, Langan D. Recommendations for quantifying uncertainty in the summary intervention effect and estimating between-study heterogeneity variance in random-effects meta-analysis. Cochrane Database Syst Rev. 2015;Supplement 1:25-7.

16. Begg CB, Mazumdar M. Operating characteristics of a rank correlation test for publication bias. Biometrics. 1994;50(4):1088-101. 
17. Egger M, Davey Smith G, Schneider M, Minder C. Bias in meta-analysis detected by a simple, graphical test. BMJ. 1997;315(7109):629-34.

18. Bech GJ, Pijls NH, De Bruyne B, Peels KH, Michels HR, Bonnier HJ, Koolen JJ. Usefulness of fractional flow reserve to predict clinical outcome after balloon angioplasty. Circulation. 1999;99(7):883-8.

19. Nam CW, Hur SH, Cho YK, Park HS, Yoon HJ, Kim H, Chung IS, Kim YN, Kim KB, Doh JH, Koo BK, Tahk SJ, Fearon WF. Relation of fractional flow reserve after drug-eluting stent implantation to one-year outcomes. Am J Cardiol. 2011;107(12):1763-7.

20. R Core Team. R: A Language and Environment for Statistical Computing. R Founda- tion for Statistical Computing 2015, Vienna, Austria. URL http://www.R-project.org.

21. Viechtbauer $\mathbf{W}$. Conducting meta-analyses in $\mathrm{R}$ with the metafor package. J Stat Softw. 2010;36:1-48.

22. Doh JH, Nam CW, Koo BK, Lee SY, Choi H, Namgung J, Kwon SU, Kwak J, Kim HY, Choi WH, Lee WR. Clinical Relevance of Poststent Fractional Flow Reserve After Drug-Eluting Stent Implantation. J Invasive Cardiol. 2015;27(8):346-51.

23. Ito $\mathrm{T}$, Tani $\mathrm{T}$, Fujita $\mathrm{H}$, Ohte $\mathrm{N}$. Relationship between fractional flow reserve and residual plaque volume and clinical outcomes after optimal drugeluting stent implantation: insight from intravascular ultrasound volumetric analysis. Int J Cardiol. 2014;176(2):399-404.

24. Reith S, Battermann S, Hellmich M, Marx N, Burgmaier M. Correlation between OCT-derived intrastent dimensions and fractional flow reserve measurements after coronary stent implantation and impact on clinical outcome. J Invasive Cardiol. 2015;27(5):222-8.

25. Fischman DL, Leon MB, Baim DS, Schatz RA, Savage MP, Penn I, Detre K, Veltri L, Ricci D, Nobuyoshi M, Cleman M, Heuser R, Almond D, Teirstein PS, Fish RD, Colombo A, Brinker J, Moses J, Shaknovich A, Hirshfeld J, Bailey S, Ellis S, Rake R, Goldberg S. A randomized comparison of coronary-stent placement and balloon angioplasty in the treatment of coronary artery disease. Stent Restenosis Study Investigators. N. Engl J Med. 1994;331(8):496-501.

26. Serruys PW, de Jaegere P, Kiemeneij F, Macaya C, Rutsch W, Heyndrickx G, Emanuelsson H, Marco J, Legrand V, Materne P, Belardi J, Sigwart U, Colombo A, Goy JJ, van den Heuvel P, Delcan J, Morel A. A comparison of balloon-expandable-stent implantation with balloon angioplasty in patients with coronary artery disease. Benestent Study Group. N Engl J Med. 1994; 331(8):489-95.

27. Johnson NP, Toth GG, Lai D, Zhu H, Acar G, Agostoni P, Appelman Y, Arslan F, Barbato E, Chen SL, Di Serafino L, Dominguez-Franco AJ, Dupouy P, Esen AM, Esen OB, Hamilos M, Iwasaki K, Jensen LO, Jimenez-Navarro MF, Katritsis DG, Kocaman SA, Koo BK, Lopez-Palop R, Lorin JD, Miller LH, Muller O, Nam CW, Oud N, Puymirat E, Rieber J, Rioufol G, Rodes-Cabau J, Sedlis SP, Takeishi Y, Tonino PA, Van Belle E, Verna E, Werner GS, Fearon WF, Pijls NH, De Bruyne B, Gould KL. Prognostic value of fractional flow reserve: linking physiologic severity to clinical outcomes. J Am Coll Cardiol. 2014;64(16):1641-54.

28. Hanekamp CE, Koolen JJ, Pijls NH, Michels HR, Bonnier HJ. al. Comparison of quantitative coronary angiography, intravascular ultrasound, and coronary pressure measurement to assess optimum stent deployment. Circulation. 1999:99(8):1015-21.

29. Fearon WF, Luna J, Samady H, Powers ER, Feldman T, Dib N, Tuzcu EM, Cleman MW, Chou TM, Cohen DJ, Ragosta M, Takagi A, Jeremias A, Fitzgerald PJ, Yeung AC, Kern MJ, Yock PG. Fractional flow reserve compared with intravascular ultrasound guidance for optimizing stent deployment. Circulation. 2001;104(16):1917-22.

30. Stempfle HU, Konig A, Drescher E, Siebert U, Klauss V. Discrepancy between morphologic and functional criteria of optimal stent deployment using intravascular ultrasound and pressure derived myocardial fractional flow reserve. Int J Cardiovasc Intervent. 2005;7(2):101-7.

31. Pijls NH, Klauss V, Siebert U, Powers E, Takazawa K, Fearon WF, Escaned J, Tsurumi Y, Akasaka T, Samady H, De Bruyne B. Coronary pressure measurement after stenting predicts adverse events at follow-up: a multicenter registry. Circulation. 2002;105(25):2950-4

32. Applegate RJ, Sacrinty MT, Kutcher MA, Santos RM, Gandhi SK, Little WC. Effect of length and diameter of drug-eluting stents versus bare-metal stents on late outcomes. Circ Cardiovasc Interv. 2009;2(1):35-42.

33. Caputo RP, Goel A, Pencina M, Cohen DJ, Kleiman NS, Yen CH, Waksman R, Tolerico P, Dhar G, Gordon P, Bach RG, Lopez JJ. Impact of drug eluting stent length on outcomes of percutaneous coronary intervention (from the EVENT registry). Am J Cardiol. 2012;110(3):350-5.
34. Kobayashi Y, De Gregorio J, Kobayashi N, Akiyama T, Reimers B, Finci L, Di Mario C, Colombo A. Stented segment length as an independent predictor of restenosis. J Am Coll Cardiol. 1999;34(3):651-9.

35. De Bruyne B, Hersbach F, Pijls NH, Bartunek J, Bech JW, Heyndrickx GR, Gould KL, Wijns W. Abnormal epicardial coronary resistance in patients with diffuse atherosclerosis but 'Normal' coronary angiography. Circulation. 2001;104(20):2401-6.

36. Rieber J, Schiele TM, Erdin P, Stempfle HU, Konig A, Erhard I, Segmiller T, Baylacher M, Theisen K, Haufe MC, Siebert U, Klauss V. Fractional flow reserve predicts major adverse cardiac events after coronary stent implantation. Z Kardiol. 2002;91 Suppl 3:132-6.

\section{Submit your next manuscript to BioMed Central and we will help you at every step:}

- We accept pre-submission inquiries

- Our selector tool helps you to find the most relevant journal

- We provide round the clock customer support

- Convenient online submission

- Thorough peer review

- Inclusion in PubMed and all major indexing services

- Maximum visibility for your research

Submit your manuscript at www.biomedcentral.com/submit
C) Biomed Central 